\title{
Pulmonary epithelioid hemangioendothelioma imitating lung cancer
}

Mariusz Łochowski ${ }^{1}$, Marek Rębowski ${ }^{1}$, Dorota Jesionek-Kupnicka², Józef Kozak ${ }^{1}$

${ }^{1}$ Department of Thoracic Surgery, Medical University of Lodz, Memorial Copernicus Hospital, Lodz, Poland

${ }^{2}$ Department of Pathology, Memorial Copernicus Hospital, Lodz, Poland

Kardiochirurgia i Torakochirurgia Polska 2017; 14 (3): 209-210

A 62-year-old man, a smoker, was admitted to our department with a history of cough, weight loss $(5 \mathrm{~kg}$ per 3 months) and fever. The physical examination revealed weakened vesicular murmur over the upper right lobe of the lung. Chest radiography exposed consolidation in the right upper lobe (RUL). Computed tomography (CT) scans of the chest revealed a solid mass in the RUL (Fig. 1). Ab-
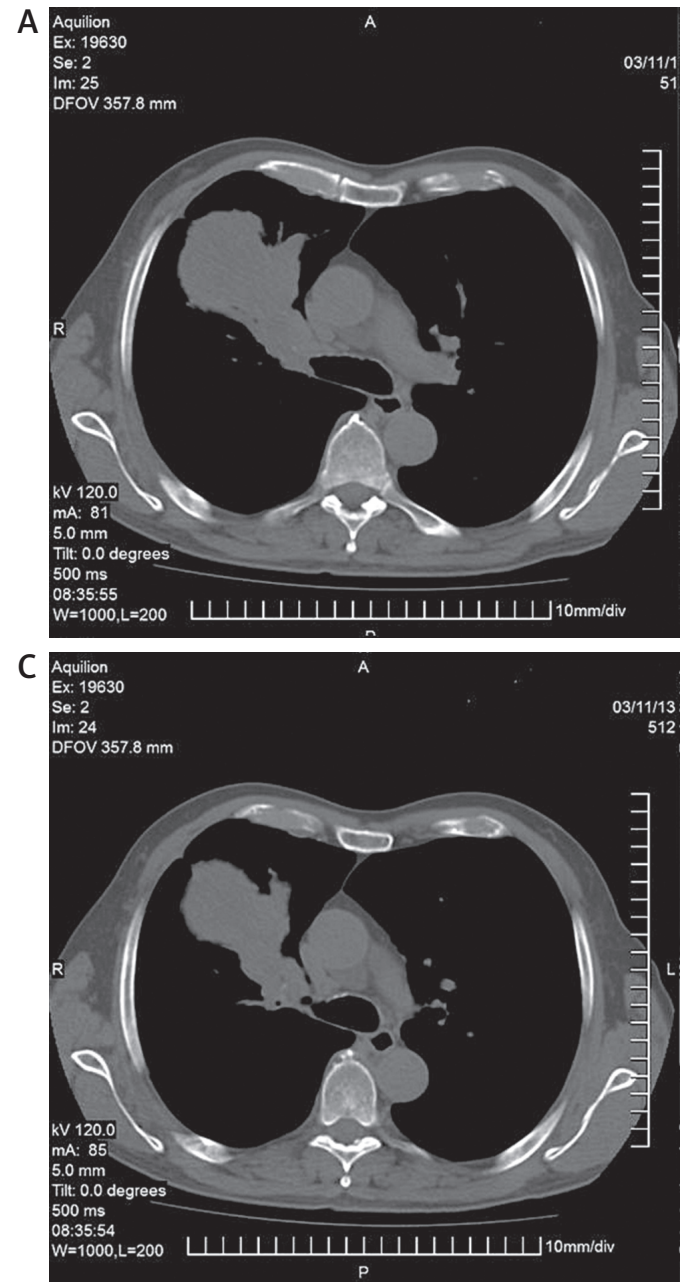

Fig. 1. Chest computed tomography scans: tumor of upper right lobe with hilar infiltration

Address for correspondence: Mariusz Łochowski MD, Department of Thoracic Surgery, Medical University of Lodz, Memorial Copernicus Hospital, 62 Pabianicka St, 93-513 Lodz, Poland, phone: +48 602776 887, e-mail: marilo@op.pl

Received: 24.11.2016, accepted: 30.12.2017. dominal ultrasound did not expose any liver metastases. Bronchoscopic examination revealed a keratotic mass in the RUL bronchus (Fig. 2). The histological examination of the mass specimen detected necrosis of tissue. Fine needle biopsy of the chest tumor was negative. The patient was scheduled for surgery for suspected carcinoma. Right antero-lateral thoracotomy was performed with upper right

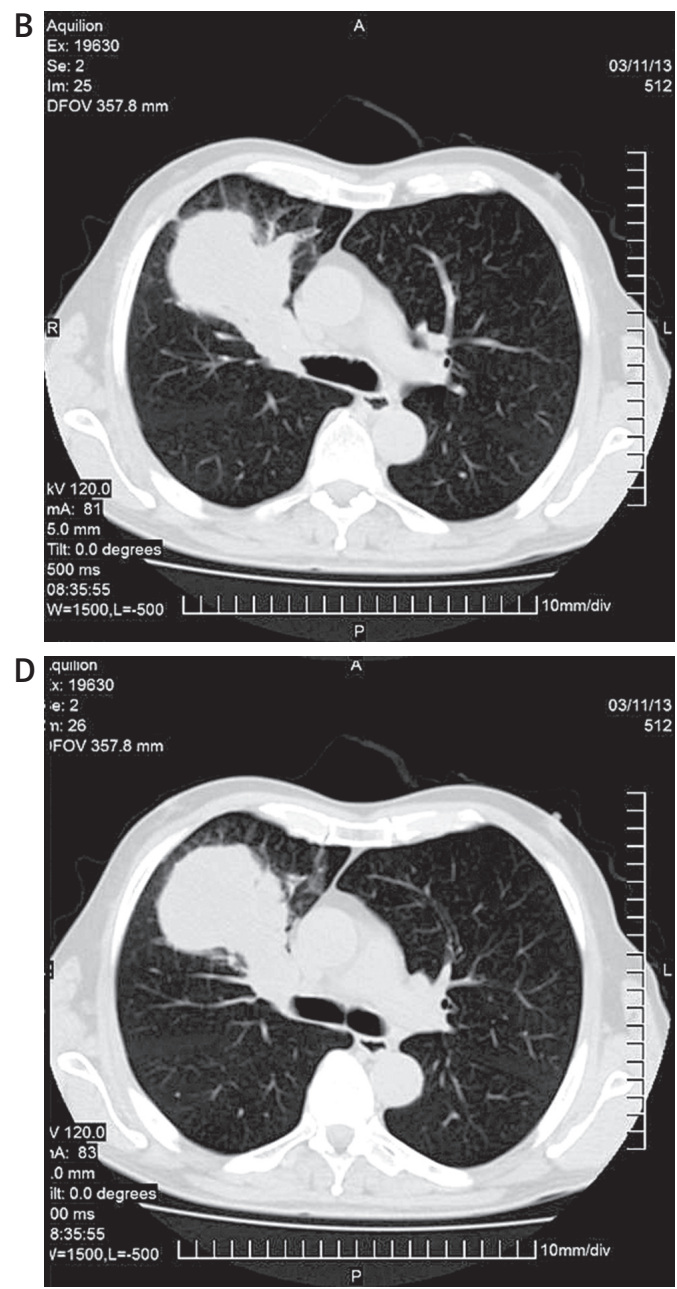




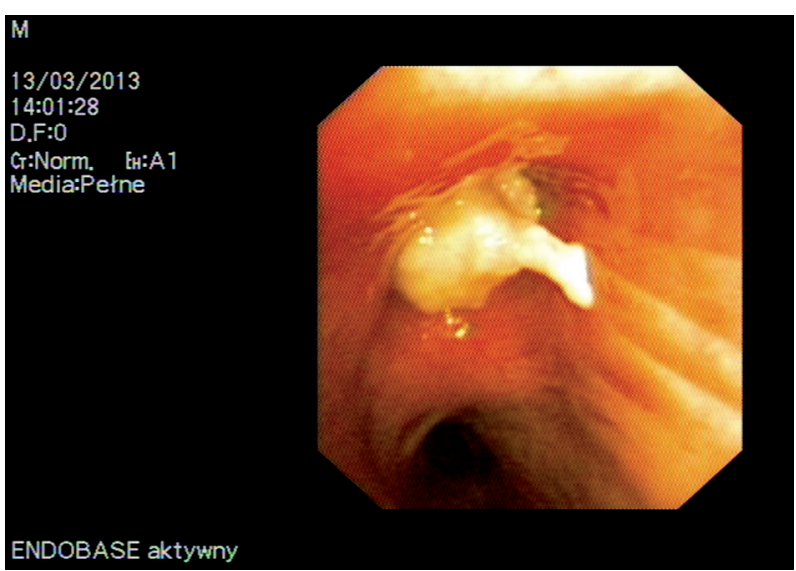

Fig. 2. Bronchoscopic examination - necrotic tissues in upper right lobe

lobectomy and lymphadenectomy. There were no complications after surgery. The patient was hospitalized for 6 days. Histological examination revealed pulmonary epithelioid hemangioendothelioma (PEH). The diagnosis was
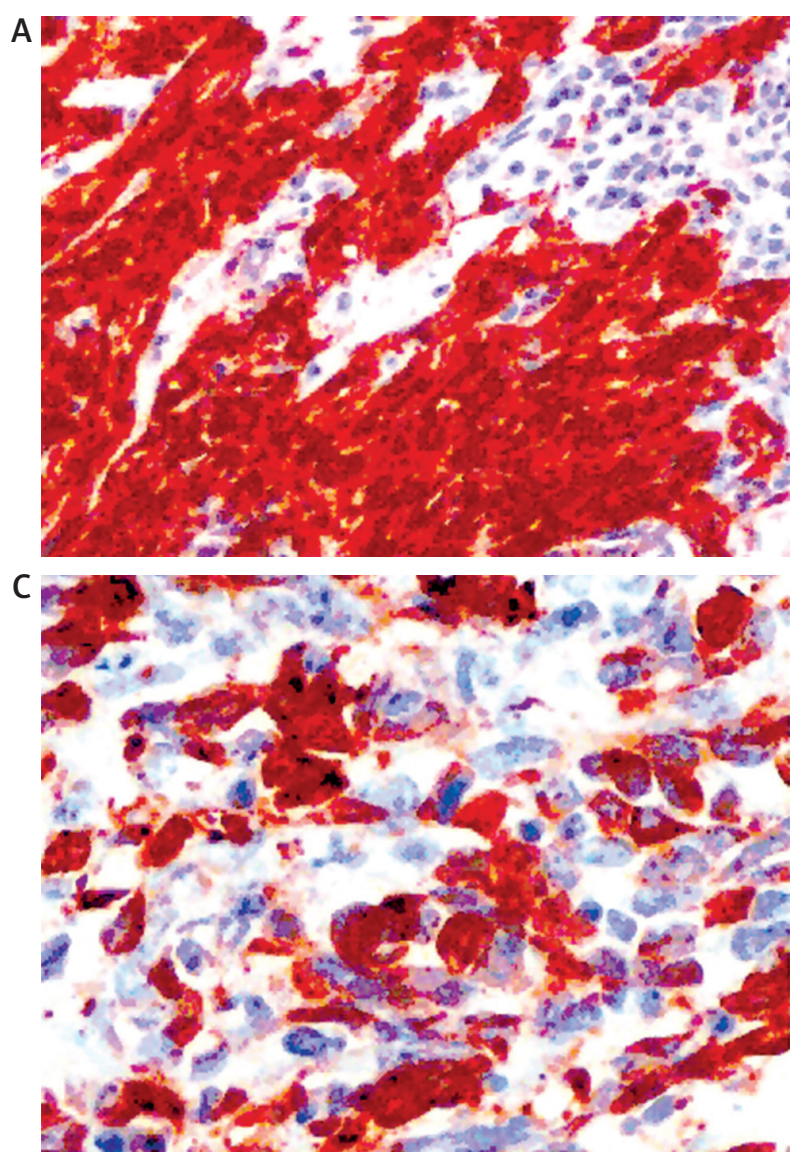

confirmed by immunohistochemical staining (Fig. 3). After 3 years of follow-up care our patient is alive without recurrence of the disease.

The PEH is a rare vascular tumor composed of endothelial cells characterized by epithelioid appearance [1]. This neoplasm was originally described in 1975 by Dail and Liebow as intravascular sclerosing bronchioalveolar tumor [2]. Prevalence is estimated at 1 in 1 million. The PEH typically manifests radiologically as multiple small unilateral $(23.7 \%)$ or bilateral (76.2\%) pulmonary nodules [1]. A very rare clinical finding is mimicking of bronchogenic carcinoma, as in our study [3]. Usually the patient is female, aged under 40, and complains of chest pain, cough, dyspnea, or rarely hemoptysis [1, 2]. Percutaneous and transbronchial biopsies are nondiagnostic and video-assisted thoracoscopy or thoracotomy is necessary in order to establish the diagnosis [3]. Prognosis of PEH is unpredictable; life expectancy ranges from 1 to 15 years [3].

\section{Disclosure}

Authors report no conflict of interest.
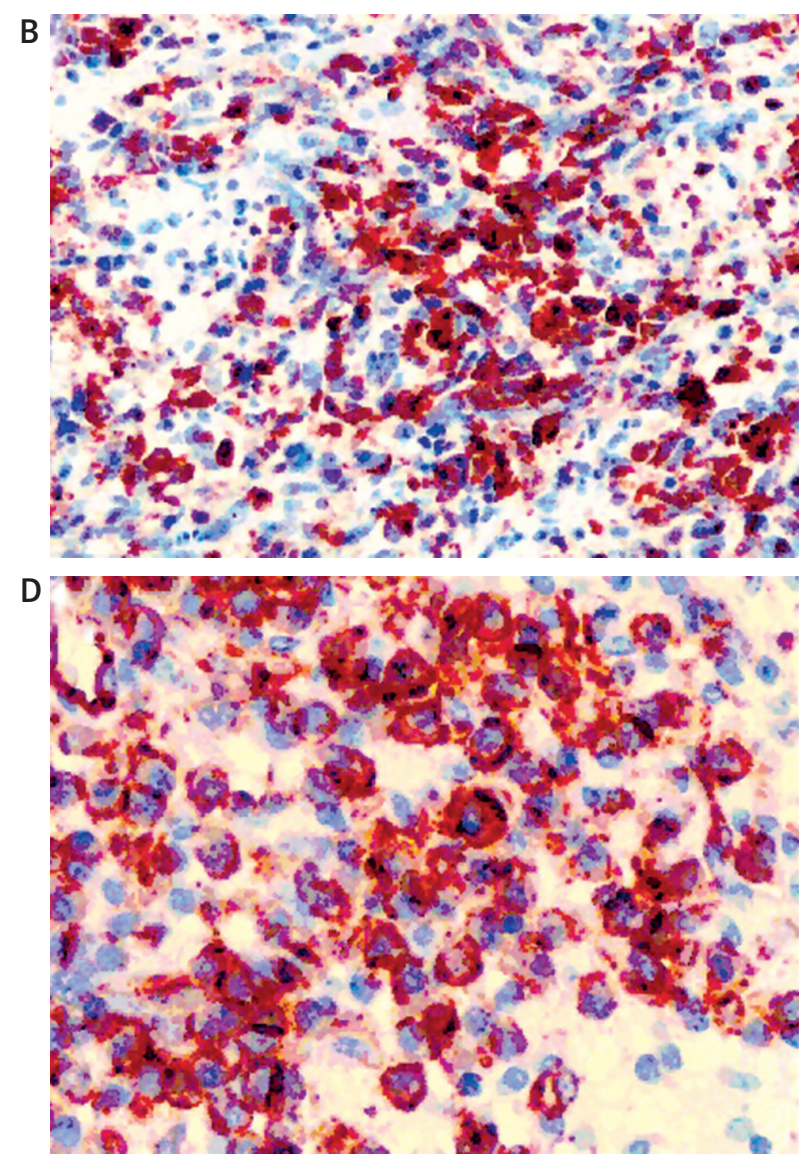

Fig. 3. Immunohistochemistry revealed strong expression of the anti-pan cytokeratin (AE1/AE3): A - in spindle cells (CKAE1/AE3, DAKO, hematoxylin counterstaining, 200×), B, C - in epithelioid cells (CKAE1/AE3, DAKO, hematoxylin counterstaining, 200× and 400x), D - endothelial marker anti-CD31 in epithelioid cells (CD31, DAKO, hematoxylin counterstaining, 400×)

\section{References}

1. Kim M, Chang J, Choi H, Oh IJ, Park CK, Kim YC, Choi YD, Yun JS, Song SY, Na KJ. Pulmonary epithelioid hemangioendothelioma misdiagnosed as a benign nodule. World J Surg Oncol 2015; 13: 107.

2. Shao J, Zhang J. Clinicopathological characteristics of pulmonary epithelioid hemangioendothelioma: a report of four cases and review of the literature. Oncol Letters 2014; 8: 2517-2522.
3. Massera F, Delfani R, Rocco G, Antonelli P, Donghi M, Robustellini M. Pulmonary epithelioid hemangioendotelioma mimicking bronchogenic carcinoma. J Cardiovasc Surg 2004; 45: 397-398. 